\title{
Bardet Biedl Syndrome
}

\author{
Ghosh TN${ }^{1}$, De S ${ }^{2}$, Pati $S^{3}$, Kumar $\mathrm{P}^{4}$, Chaki B \\ ${ }^{1}$ Dr. Taraknath Ghosh, MBBS, MD, Associate Professor, \\ ${ }^{2}$ Dr. Sangita De, MBBS, Post Graduate Trainee, \\ ${ }^{3}$ Dr. Sananda Pati, MBBS, Post Graduate Trainee, \\ ${ }^{4}$ Dr. Prabhat Kumar, MBBS, Post Graduate Trainee, \\ ${ }^{5}$ Dr. Bhusan Chaki, MBBS, Post Graduate Trainee. All \\ from the Department of Paediatrics, Burdwan Medical \\ College and Hospital, Burdwan, India.
}

\section{Introduction}

$B_{d}^{a}$ ardet-Biedl syndrome is a rare autosomal recessive disorder with cardinal symptoms of central obesity, retinal dystrophy, polydactyly, mental retardation and hypogonadism and renal dysfunction. ${ }^{1}$ The frequency of the syndrome is estimated to be $1: 1,60,000^{2}$. Less than 15 cases have been reported from India ${ }^{3}$. The incidence is higher in populations with a high level of consanguinity. Clinical diagnosis is based on the presence of 4 of the 5 cardinal features ${ }^{1}$.

The authors present a classical case of Bardet Biedl syndrome presenting to paediatrics outpatient department with childhood obesity, mild mental retardation with polydactyly of all four limbs, and later on found to have retinitis pigmentosa and hypoplastic uterus, fallopian tubes with bilateral small ovaries with mild structural anomaly of both kidneys. There was history of consanguinous marriage in parents and presence of similar features in a relative.

\section{The Case}

Our patient was a eight year old girl, born to consanguinuos marriage, with birth weight $3 \mathrm{~kg}$ and length $50 \mathrm{~cm}$, presented to paediatric outpatient department with obesity and night blindness. she had a second degree relative with similar features in her family. Physical examination revealed presence of central obesity with polydactyly and brachydactyly of both hands and feet. ophthalmic examination revealed atypical retinitis pigmentosa with low visual acuity (6/60 both eye). ultrasonographic examination showed hypoplastic fallopian tube and uterus with bilateral small ovaries. There was mild renal anomaly. She was 125

\begin{abstract}
This is a case report of Bardet-Biedl syndrome, diagnosed in a 8 year old girl presented with obesity. She had polydactyly, mild mental retardation, retinitis pigmentosa in both eyes, with hypoplastic uterus, fallopian tube and ovaries. She was born to a consanguinous marriage and had a family member with same features.
\end{abstract}

Key words: Bardet biedl syndrome, Polydactyly

$\mathrm{cm}$ tall and weighted $50 \mathrm{~kg}$ with resulting BMI 32. Her IQ was 70 . MRI brain was normal. History and physical examination suggested that the patient was suffering from a rare cause of childhood obesity, Bardet Biedl syndrome. Parents of the patient was counselled and advised for regular follow up for development of renal disease and progression of visual problem.

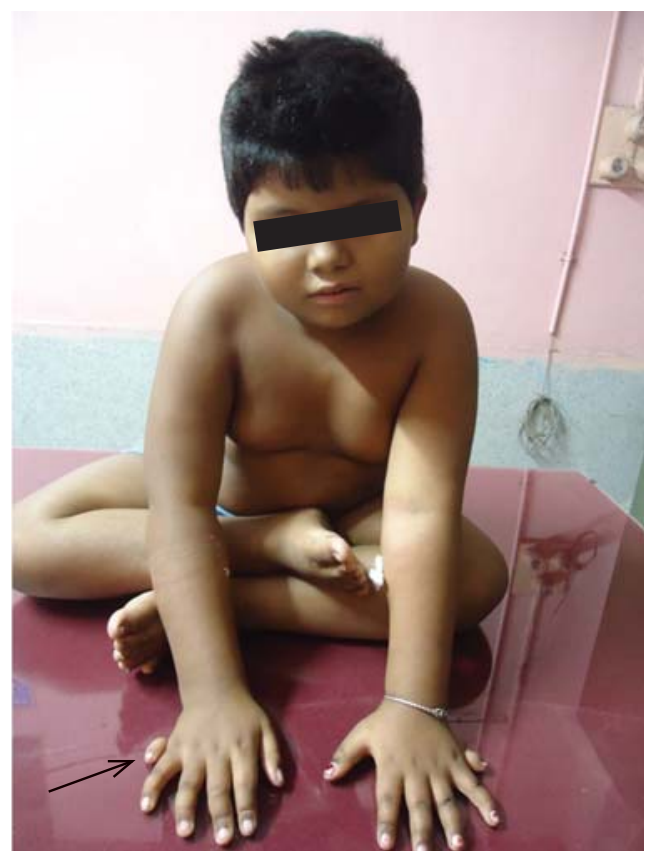

Fig 1: Polydactyly, brachydactlyly of hands

\section{Address for correspondence \\ Dr. Sangita De \\ E-mail: sangita.de6@gmail.com}

\section{How to cite this article?}

Ghosh TN, De S, Pati S, Kumar P, Chaki B. Bardet Biedl Syndrome. J Nepal Paediatr Soc 2013;33(2):129-131. 


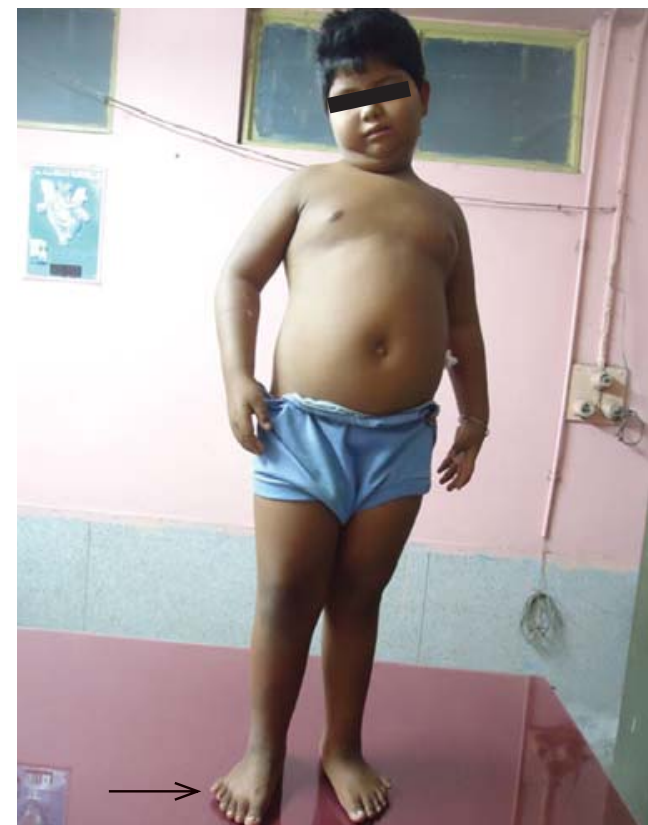

Fig 2: Central obesity and polydactyly of feet

\section{Discussion}

Bardet-Biedl syndrome (BBS) is a rare autosomal recessive disorder with clinical and genetic heterogeneity. This syndrome was first described by Laurence and Moon in 1866 and additional cases were described by Bardet and Biedl between 1920 and $1922^{4}$. BBS was formerly grouped with Laurence-Moon-Biedl syndrome, but today is considered as a separate entity. It has autosomal recessive inheritance characterized by retinal dystrophy or pigmentary retinopathy, polydactyly, obesity, mental retardation, hypogonadism and hypogenitalism in males, amenorrhea in females and structural abnormalities or functional impairment of kidney, $5,6,7$. Other clinical features include speech disorder, brachydactyly, developmental delay, polyuria and polydipsia, ataxia, poor coordination/clumsiness, diabetes mellitus, left ventricular hypertrophy, hepatic fibrosis, and renal hypoplasia/dysplasia. BardetBiedl syndrome is both phenotypically and genetically heterogeneous.

Bardet-Biedl syndrome is genetically heterogeneous, with 12 BBS genes (BBS1â€"12) identified to date ${ }^{3-10}$. Although the cellular mechanisms that underlie BBS remain unclear, it is now evident that all of the known BBS proteins are components of the centrosome and/or basal body and have an impact on ciliary transport ${ }^{8}$. The BBS1, BBS2, BBS3 and BBS4 genes contribute to ocular phenotype ${ }^{9,10}$. The BBS10 gene encodes a vertebrate-specific chaperoninlike protein ${ }^{11}$ The BBS5-9 and BBS11 genes are expressed in adipose tissue ${ }^{12,13}$. The BBS12 gene is vertebrate specific and, together with BBS6 and BBS10 genes, defines a novel branch of type-Il chaperonin superfamily ${ }^{14}$.
Our patient presented with features of central obesity, mild mental retardation, polydactyly and brachydactyly, atypical retinitis pigmentosa, hypoplastic uterus, fallopian tubes and bilateral small ovaries with mild renal structural anomaly. Her parents was counselled and advised for regular follow for renal problem, visual difficulty and pubertal problems.

\section{References}

1. Beales PL, Elcioglu N, Woolf AS, Parker D, Flinter FA. New criteria for improved diagnosis of BardetBiedl syndrome: Results of a population survey. $J$ Med Genet 1999;36:437-46.

2. Klein D, Ammann F. The syndrome of LaurenceMoon- Bardet-Biedl and allied diseases in Switzerland. Clinical, genetic and epidemiological studies. J Neurol Sci 1969;9:479-513

3. Hooda AK, Karan SC, Bishnoi JS, Nandwani A, Sinha T. Renal transplant in a child with BardetBiedl syndrome: A rare cause of end-stage renal disease. Indian J Nephrol 2009;19:112-4.

4. Kenneth lyons Jones. Bardet-Biedl syndrome: Smith's Recognizable Patterns of Human Malformation 5th edition, saunders company; 1997. p.590-591

5. lannello S, Fagone S, Grasso G, et al. A case of familial Bardet-Biedl syndrome (obesity, slightmental retardation, hoydactyly, retinitis pigmentosum and renal failure) with insulin-resistant diabetes mellitus. Minerva Endocrinol 1998;23:83-92.

6. David A, Bitoun P, Lacombe D, et al. Hydrometrocolpos and polydactyly: a common neonatal presentation of Bardett-Biedl and McKusick-Kaufman syndromes. J Med Genet 1999;36:599-603.

7. Hrynchak PK. Bardet-Biedl syndrome. Optom Vis Sci 2000;77:236-243.

8. Beales PL. Lifting the lid on Pandora's box: the Bardet-Biedl syndrome. Curr Opi Genet Dev 2005;15:315-323.

9. Heon E, Westall C, Carmi R, Elbedour K. Ocular phenotypes of three genetic variants of Bardet-Biedl syndrome. Am J Med Genet 2005;132(3):283-7.

10. Azari AA, Aleman TS, Cideciyan AV, Schwartz SB. Retinal disease expression in Bardet-Biedl syndrome-1 (BBS1) is a spectrum from maculopathy to retina-wide degeneration. Invest Ophthalmol Vis Sci 2006;47(11):5004-10.

11. Stoetzel C, Laurier V, Davis EE, Muller J. BBS10 encodes a vertebrate-specific chaperonin-like protein and is a major BBS locus. Nat Genet 2006;38(5):521-4. 
12. Forti E, Aksanov O, Birk RZ. Links Temporal expression pattern of Bardet-Biedl syndrome genes in adipogenesis Int $\mathrm{J}$ Biochem Cell Biol 2007;39(5):1055-62.

13. Benzinou M, Walley A, Lobbens S, Charles MA. Bardet-Biedl Syndrome Gene Variants Are Associated With Both Childhood and Adult
Common Obesity in French Caucasians. Diabetes 2006;55:2876-2882.

14. Stoetzel C, Muller J, Laurier V, Davis EE, Zaghloul NA. Identification of a novel BBS gene (BBS12) highlights the major role of a vertebrate-specific branch of chaperonin related proteins in Bardet-Biedl syndrome. Am J Hum Genet 2007 Jan;80(1):1-11. 